\title{
A Short Online Course Targeting Professionalism, The Impact Of ENGINEERING ON SocieTY AND THE ENVIRONMENT, AND ETHICS AND EQUiTy
}

\author{
Nasim Razavinia and Laurent Mydlarski \\ Faculty of Engineering, McGill University \\ nasim.razavinia@mcgill.ca laurent.mydlarski@mcgill.ca
}

\begin{abstract}
Understanding the role and responsibilities of Professional Engineers is of immediate relevance to those who aspire to enter the profession. These obligations most prominently manifest themselves in three of the twelve graduate attributes: Professionalism; the Impact of engineering on society and the environment; and Ethics and equity. Following an analysis of the curriculum map of programs that was performed as part of the CEAB-mandated Continual Improvement process at McGill University, it was concluded that our students could benefit from additional training in the aforementioned three graduate attributes. To this end, a required, 0-credit, online course was created to further expose and train Engineering students in all programs on these three important topics. The present paper will $i$ ) review the motivation behind the creation of this new course, ii) describe the evolution of its format and design, and iii) discuss the course's contents and implementation.
\end{abstract}

Keywords: online course, Graduate Attributes, Ethics and equity, Professionalism, Impact of engineering on society and the environment

\section{INTRODUCTION}

In all Engineering curricula, there are courses or sections of courses dedicated to providing Engineering students with appropriate information to help them understand their professional responsibilities and obligations. Although this might not be evident to the students, an understanding of i) their role as professional engineers in society, ii) the impact their professional decisions have on society and the environment, and iii) the Code of Ethics of their profession plays a critical role in their education and complements their technical training.
Furthermore, following the move toward outcomes-based assessment of Engineering programs, the Canadian Engineering Accreditation Board (CEAB) introduced twelve graduate attributes that programs are to evaluate. Of these twelve, three (Professionalism, the Impact of engineering on society and the environment, and Ethics and equity - the $8^{\text {th }}, 9^{\text {th }}$, and $10^{\text {th }}$ graduate attributes, respectively) are focused on the aforementioned competencies. However, in many, if not most, Engineering curricula, the fraction of the curriculum devoted to these subjects is much smaller than those devoted to other, more technical, topics.

At McGill, the competencies that are assessed by three Graduate Attributes in question are principally covered in two courses taken by all undergraduate engineering students in the Faculty: i) "FACC 100: Introduction to the Engineering Profession," which is taken by first-year Engineering students, and ii) "FACC 400: Engineering Professional Practice," which is taken by final-year Engineering students. Moreover, an analysis of the curriculum maps of the programs was performed, as part of the CEAB-mandated Continual Improvement process (CEAB Criterion 3.2). It was concluded that although the competencies in question were studied in the first and final years of our programs, they were less frequently addressed in the middle of the curricula. To further educate students on these topics and reinforce their importance in the middle of their studies, a new course - focussing on material relevant to the aforementioned three graduate attributes entitled "FACC 250: Responsibilities of the Professional Engineer" was created and added as a required course in all our programs. (The number 250 was chosen as it was the average of 100 and 400, thus representing the mid-point of programs - i.e., the time in the program at which we were choosing to reinforce these subjects.)

The purpose of this paper is to, therefore, share our experience in developing this online course in the Faculty of Engineering, to better prepare our undergraduate students for their future professional obligations. 


\section{MOTIVATION BEHIND THE CREATION OF A NEW COURSE}

To provide some context on the origin of this course, we first remark that McGill's Faculty of Engineering created a new committee in 2013, named the Continuous Program Evaluation and Improvement (CPEI) Committee, which is chaired by the Associate Dean (Academic Programs). This committee was tasked with implementing the CEABmandated i) assessment of Graduate Attributes (CEAB Criterion 3.1), and ii) Continual Improvement process (CEAB Criterion 3.2), with the objective of identifying any areas requiring improvement in each program, and addressing departmental concerns and recommendations following the analysis and interpretation of the data gathered during the Graduate Attribute assessment process.

In 2016, the curriculum maps of all Engineering programs in the Faculty were reviewed. In the same year, the CEAB published a rubric [4] that defined the minimum number of learning activities/courses in which graduate attributes were assessed to be three (per attribute). Given the new rubric, the CPEI Committee concluded that most programs would benefit from the addition of a new course in which the $8^{\text {th }}, 9^{\text {th }}$, and $10^{\text {th }}$ graduate attributes could be rigorously and repeatedly assessed. This new course, which ultimately became FACC 250: Responsibilities of the Professional Engineer, was designed to complement the two courses already in place (FACC 100 and FACC 400). Given that FACC 100 and FACC 400 were taken at the beginning and end of programs, respectively, it was deemed best to incorporate the new course during the second or third year of the programs, to ensure a regular, repeated exposure to the topics in question.

The discussion then shifted towards the length of the course. The committee members unanimously agreed that the programs were already heavy, and that students' schedules were already busy satisfying the other requirements of their programs. Thus, the addition of an extra course to their schedule could cause conflicts, no break between classes, and/or an excessive increase in workload. Therefore, a self-paced, short course was more favorable than a full (3-credit, 13-week) course. Moreover, since tuition fees in Quebec universities are based on the number of credits in which students are registered, the addition of a course would add to the students' fees. The Faculty agreed to absorb the costs associated with this new course and offer it as a zero-credit course, to minimize the impact on students.

\section{FORMAT OF THE COURSE}

The decision to offer a self-paced course then led to decisions pertaining to its format. In addition to traditional face-to-face courses, technological advancements in education have led to a variety of other teaching and learning formats that are practiced in many universities. These formats include web-facilitated or web-enhanced face-to-face courses (that have replaced the traditional, uniquely face-to-face courses), hybrid courses, and online courses. Although most readers will be familiar with these formats, we nonetheless define these terminologies before discussing the choice we made for FACC 250, to eliminate any possible confusion.

As most of us have experienced, both as students and as instructors, traditional face-to-face courses are courses that do not employ online technology. All the content is delivered by the instructor in person, in writing or orally [1]. However, such courses are rarely self-paced.

A web-enhanced or web-facilitated course is a traditional course that includes technology-mediated elements. The use of learning management platforms and specific software to complete assignments and/or labs are among the many technologies that can be used by the instructors. However, a web-enhanced course does not reduce the face-to-face time that students spend in class.

A hybrid or blended course is a course in which some of the learning activities that would normally take place in a classroom in the presence of the instructor are replaced by online learning activities. Such courses are less restrictive on students' and instructors' schedules than traditional or web-facilitated courses, because the face-toface contact time is significantly reduced by employing web-technologies to transfer course materials.

In online courses, $80 \%$ to $100 \%$ of the course is delivered online, with minimal to no face-to-face interactions with the instructor [1]. Moreover, online courses can be offered in either synchronous or asynchronous fashions.

Given that the CPEI Committee had decided that it was best if students completed the course at their own pace (according to their schedule), an online course offered with asynchronous delivery was deemed to be the most appropriate course delivery mode for FACC 250. Although this would be first fully online required course in Engineering programs at McGill, the CPEI Committee was optimistic regarding the success of students taking this course in meeting their learning outcomes given that prior research has demonstrated that there were no significant differences in student performance in online versus webenhanced face-to-face delivery of a course [8].

\section{COURSE CREATION METHODOLOGY}

Given the choice of an online, asynchronous course in which there were no face-to-face interactions between students and the instructor, it is especially crucial to create engaging and organized content, channels of communication, a guiding visual design, and different modes of assessments. 
As in any instructional design, the development and design of online courses is an iterative process [10]. According to the ADDIE model [5], the design of a course compromises five main phases: Analysis, course content Design, course Development, course Implementation, and course Evaluation.

The analysis was performed by the CPEI Committee, which consisted of understanding the educational "problem" and the design of an initial solution, while considering all constraints/restrictions. During this phase, the course objectives were set, and the students' prior knowledge was accounted for [6].

The learning objectives, course structure, course content, and assessment methods are selected in the design phase. Section 5 below describes the design phase of the course's creation.

The course development phase, discussed in Section 6, involves the creation and collection of the course's content in different forms. In this phase, the content of the course is drafted, and the graphics and various modes of the course delivery are assembled.

During the implementation phase, all components of the course are tested to ensure a proper transition from one element to the next. This is the time at which the course is put into practice; all content is uploaded, and all configurations are set [2].

The evaluation phase provides opportunities for the user(s) to provide feedback. This feedback is compared with the course objectives. In this phase, the course materials can be reviewed and improved [7]. Section 7 of this paper covers both the Implementation and the Evaluation phases of the course's creation.

\section{COURSE DESIGN}

\subsection{Structure of the Course}

Online courses can be offered in non-modular, or modular formats.

A non-modular course structure is one in which i) all course content (e.g. readings, videos, assessments, discussion forums, etc.) is provided to the students, and ii) students are required to navigate the course according to the course syllabus and timetable for the deliverables.

When a modular course structure is employed, the course content is divided into multiple sections. Each module contains all of the course materials and assessments for that section. The advantage of a modular structure is that it provides more guidance to the students. Since each module contains all the study materials for that section, students are assured that they are not missing any part of the course. Moreover, it allows instructors to set both global course learning outcomes and modular learning outcomes [7].
Since the present course consists of three distinct topics, it naturally lent itself to a modular course structure. Each module contains the course content and concludes with an end-of-module quiz. Successful completion of each module is required to pass the course.

\subsection{Course Content}

The first step in establishing the course content for FACC 250 was a review of the two existing courses (FACC 100 and FACC 400), to ensure the continuity of the subject matter between the courses.

The learning outcomes for FACC 250 were then determined. Upon completion of FACC 250, students should be able to:

- Describe the responsibilities and obligations of engineers

- Understand protecting the public and its interest

- Describe professional accountability

- Understand sustainable development and environmental stewardship

- Understand sustainable design and sustainable Engineering

- Understand Life Cycle Assessment

- Apply knowledge of ethics to evaluate situations in engineering practice

- Demonstrate the understanding of equity issues in engineering practice

The three modules, summarized below, were then developed to help students achieve the aforementioned learning outcomes.

5.2.1 Professionalism. This module is based on the "Document d'étude - Examen professionnel" provided by the Ordre des ingénieurs du Québec (OIQ), which is a study guide for the OIQ's professional practice exam taken by applicants for professional licensure in the province of Québec. The present module focuses on Québec's professional law and the legal context. The materials are presented in a simple format, to introduce students to Quebec's legislation respecting the professions (i.e. the Professional Code, the Engineers Act), and provide them with basic knowledge of the legal liabilities of licensed engineers in the province of Québec.

5.2.2 Impact of Engineering on Society and the Environment. Although all Engineering students at McGill, as part of their degree requirements, must take an elective course focused on the "Impact of technology on society," there is no other formalized treatment of this topic in the Engineering curricula. To ensure that all students have sufficient knowledge, this module starts with a review of the definition of sustainability, its three aspects, and the 
three characteristics of the modern concept of sustainability. The concepts of sustainable development, environmental stewardship, and the "Our Common Future" guidelines are then discussed. The notion of sustainable Engineering and its principles followed by sustainable design and the Hannover principles wrap up the topic of sustainability in this module. At the end of the module, students are introduced to the concept of Life-Cycle Assessment.

5.2.3 Ethics and Equity. This final module of the course is divided into two sub-modules: 1) Ethics, and 2) Equity. The Ethics sub-module is based on the Québec Code of Ethics for Engineers. All sections of the Code of Ethics are covered in this section. The Equity sub-module focusses on a discussion of minority groups, specifically the gender gap, in the Engineering profession, and the need for diversity in the profession.

\subsection{Assessment methods}

Both formative and summative assessments are employed in this course. The formative assessment comprises self-assessments in each module. Passing or failing the self-assessments does not play a (direct) role in determining a student's successful completion of the course. The summative assessments are end-of-module quizzes. The questions are only focused on the materials covered in that module (and not the whole course). To successfully complete the course, students must pass each module with a grade of $60 \%$ or higher. Considering the assessments are performed online, it is understood that the exams are of the open-book/open-notes format. However, to ensure that the academic integrity of the exams is preserved, each student answers a different set of questions taken from a large pool of questions developed for each module. Moreover, each year, the questions are revised, or new questions are added to the pool of questions.

\section{COURSE DEVELOPMENT}

The biggest challenge in designing an online course is the adaptation of the course materials to the online environment. It is evident that online courses are different from face-to-face classes, and one cannot simply upload material developed for face-to-face courses to the web, without adaptation. Thus, the course must be designed specifically for the online medium.

The instructor and course designer of an online course should create an appropriate balance between pedagogy (e.g. the amount of course content delivered) and technology (e.g. the various tools used to deliver the course content). Therefore, in addition to the instructor's pedagogical role in the delivery of online courses, her/his managerial and technical roles become more important.
The management of the course includes setting the calendar of the course and creating rules and making decisions about the administration and execution of the course. It goes without saying that all policies and decisions must be communicated clearly and consistently during the course. Moreover, the instructor's technical role requires that she/he be comfortable with the technology being employed and being able to respond to the technical difficulties experienced by students [3],[9].

All online courses require a platform to deliver and communicate the course content. In many cases, an institution's Learning Management System (LMS) can be the logical choice, as it provides many options such as discussion forums, survey tools, quizzes, announcements, etc. over and above the capability to upload course content, videos, and audio in various formats. For our online course, the University's learning management system (D2L branded as "myCourses" at McGill University) was the chosen platform. myCourses has been used for years at McGill University and students are therefore familiar and comfortable with its use. It offers various assessment tools and automated grading for self-assessments and quizzes. Announcements and email tools also provide proper communication channels, as is typical for LMS platforms.

In the design of FACC 250, we ensured that the delivery of the course content was offered in small/short segments. The readings were of a manageable size that did not overwhelm students. The videos were short and transcripts were provided. A variety of different delivery methods, formats, and media were employed to keep students interested as the course progress. More specifically, articles and case studies were taken from publications such as the OIQ's PLAN magazine, short videos were created, with VideoScribe, to teach the Code of Ethics, and online TedTalks were used to demonstrate the environmental impact of Engineering decisions.

\section{COURSE IMPLEMENTATION AND EVALUATION}

In our experience, implementation of this short, online, modular course was a time-consuming task that required extensive attention to detail. Certain aspects that were especially laborious included verification of the course content and testing of all links, to ensure the proper functioning of the course. If possible, we recommend that someone other than the course designer / instructor review the course to avoid any ambiguous instructions or problems with the course content.

Our implementation of the course went through two iterations. In the first, the course was examined from the students' perspective once all verifications had been completed. A course guide was added, as well as an "Instructor's Welcome Note." A course map was added to the beginning of each module, and automated feedback 
was entered in the self-assessments. In the second iteration, some of the graphics were improved. A direct link to each module was created in the course homepage, and access to the end-of-module quizzes was restricted, to impede students from skipping the course materials and only attempting the exams.

As in face-to-face classes, where instructors make announcements and remind students of the upcoming deliverables and deadlines, calendar reminders and announcements were also necessary to remind students of the deadlines in this online course. Since the dates change every semester, these reminders need to be updated in every course offering. [3]

At present, FACC 250 has been offered for four semesters. Although a short, online zero-credit course, the University's regular course evaluation is performed at the end of each semester, and students' feedback is reviewed by the instructor. All comments that can serve to improve the successful delivery of the course are taken into account and implemented, where possible.

\section{FINAL COMMENTS}

In online asynchronous courses, students are required to complete the course activities autonomously, which is a valuable exercise in and of itself. Although this was not a planned outcome for this course, having to complete such a course in which they must learn independently, on their own schedule, also serves to improve students' time management and life-long learning skills - especially in a curriculum that is dominated by regularly-scheduled faceto-face courses.

One drawback that was experienced with this online course is that since the students are free to study the course materials at a time that is convenient for them, it gives them the understanding that the course, as well as the instructor, are available around the clock. For some students, this created an expectation that the instructor should be available whenever they are free to study the course. This issue manifests itself mainly in e-mails. Moreover, given that e-mail is a primary communication tool in an online course, delays in the instructor's response can create frustration on the student's behalf. One solution to this issue is to set specific office hours, similar to face-to-face courses, to provide students with an opportunity to communicate with the instructor and receive answers promptly.

\section{References}

[1] I. E. Allen and J. Seaman, "Online Nation Five Years of Growth in Online Learning", 2007, http://www.onlinelearningsurvey.com/reports/on line-nation.pdf.

[2] F. G. Constancio et al., "Extended ADDIE Model for improved Distance Learning Courses," 2018 IEEE Frontiers in Education Conference (FIE), San Jose, CA, USA, 2018.

[3] P. A. Creasman, "Considerations in Online Course Design", IDEA, Paper \#52, 2014. https://www.ideaedu.org/idea_papers/considerati ons-in-online-course-design/.

[4] Engineers Canada - Accreditation resources: https://engineerscanada.ca/sites/default/files/accr editation/gaci-rubrics-en.pdf

[5] T. Manichander, E-EDUCATION, pp. 20-21, 2016. Published by Lulu.com.

[6] S. J. McGriff, "Instructional system design (ISD): Using the ADDIE model," Instructional Systems, College of Education, Penn State University, 2000.

[7] M. Molenda, "In search of the elusive ADDIE model," Performance improvement, vol. 54, no. 2, p. 40-42, 2015.

[8] T. Ramage, "The "No Significant Difference" Phenomenon: A Literature Review," 2002. https://spark.parkland.edu/ramage_pubs/1.

[9] S. A. Riggs and K. E. Linder, "Actively Engaging Students in Asynchronous Online Classes," IDEA, $\quad$ Paper $\quad$ \#64, 2016. https://www.ideaedu.org/idea_papers/activelyengaging-students-in-asynchronous-onlineclasses/

[10]D. Verstegen, Y. Barnard, and A. Pilot, "Which events can cause iteration in instructional design? An empirical study of the design process," Instructional Science, 34, pp.481-517, 2006. 